Uludag Univ. J. Fac. Vet. Med.

34 (2015), 1,2: 95-99

\title{
Bir Koyunda Aşil Tendo Rupturu Sağaltımında Uygulanılan Kompresyon Vidası ile Geçici Calcaneo-tibial Fiksasyon
}

\author{
Melike ÇETİN ${ }^{1} \quad$ Mustafa Barış AKGÜL ${ }^{1} \quad$ Hasan KURT $^{1} \quad$ Hakan SALCI $^{1}$
}

Geliş Tarihi: 07-12-2015

Kabul Tarihi: 30-12-2015

\begin{abstract}
Özet: Merinos ırkı, 1,5 yaşlı bir koyun sağ arka ekstremitesini kullanamıyor şikayeti ile kliniklerimize getirildi. İnspeksiyonda, koyun sağ metatarsusları üzerine basmaktaydı. Aşil tendosunun palpasyonda tendojen gerginliğin olmadığı hissedildi. Tanısal görüntüleme yöntemleri yardımıyla (radyoloji ve ultrasonografi) aşil tendo rupturu tanısı doğrulandı. Genel anestezi altında rupture olmuş aşil tendosu Bunnell-Mayer yöntemi ile dikildi ve tendonun iyileşmesine destek olması için tarsal eklemin normal konumda bir kompresyon vidası ile geçici olarak calcenao-tibial fiksasyonu sağlandı. Postoperatif 2. ayda fiksasyon vidası çıkarıldığında koyunun ilgili ekstremitesini normal olarak kullandığı belirlendi.
\end{abstract}

Anahtar Kelimeler: Aşil tendo rupturu, calcaneo-tibial fiksasyon, koyun.

\section{Temporary Calcaneo-tibial Fixation with Compression Screw Applied in the Treatment of Achilles Tendon Rupture in a Sheep}

\begin{abstract}
A Merinos breed, 1,5 year-old sheep was presented to clinics with the complaint of disability problem on right hind limb. In the inspection, the sheep was setting her metatarsus down on the ground. Tendogen tension was not felt in the palpation of the achilles tendon. The achilles tendon rupture was confirmed with the help of diagnostic imaging techniques (radiology and ultrasound). The ruptured Achilles tendon was sutured with Bunnell-Mayer technique under general anesthesia, and calcaneo-tibial fixation, positioning the tarsal joint in normal situation, was performed with a compression screw for supporting the healing process temporarily. When the fixation screw was removed in the postoperative $2^{\text {nd }}$ month, it was determined that the sheep was using the extremity normally.
\end{abstract}

Key Words: Achilles tendon rupture, calcaneo-tibial fixation, sheep.

\section{Giriș}

Tendolar kollagen ipliklerin bir araya gelmesiyle oluşmaktadır. Tendoların asıl fonksiyonları, kas iskelet sisteminin hareketine kat1larak destek oluşturmaktır. Aşil tendosu ya da tendo calceneus communis, musculus gastrocnemius, musculus flexor digitorum superficialis ile musculus biceps femoris, musculus semitendinosus ve musculus gracialis kaslarının ortak kirişlerinin tuber calcanei'de son bulan tendo kordonudur $^{1-6}$. Genu ekleminin fleksiyonu, tarsal eklemin ekstensiyonu ve parmakların fleksiyonu olmak üzere üç fonksiyona sahiptir ${ }^{2}$.

Tendoların kongenital anomaliler (uzunluk-kısalık) ve travmatik (ruptur, avülzyon, laserasyon) bozuklukları en yaygın görülen patolojilerdir ${ }^{3}$. Așil tendosunun kopmaları (total veya parsiyel) genellikle tendonun orta noktas1 ya da kemiğe yapışma yerine yakın şekillenmektedir. Bazı olgularda muskülo-tendinöz ve

1 Uludağ Üniversitesi Veteriner Fakültesi Cerrahi Anabilim Dalı, 16059, Bursa, hsalci@uludag.edu.tr 
özellikle genç hayvanlarda tuber calcanei'den ayrılma tarzında tendo rupturları oluşmaktadır ${ }^{2-}$ 6.

Yaralanmış tendoda onarım için seçilen teknik ne olursa olsun peritendinöz adezyon şekillenmeden tendodaki dayanıklılığın tekrar sağlanması gerekmektedir ${ }^{3}$. Bu amaçla aşil tendo yırtığında operatif ya da konservatif tedavi yöntemleri kullanılmaktadır ${ }^{2,4,8,9}$. Konservatif tedavi sonrasi tekrarlayan yirtılma ve tendo boyu uzamasına bağlı gelişen güç kaybı en sık görülen problemler olduğundan özellikle hareketli ve genç hastalarda tercih edilen tedavi yöntemi tendonun dikilmesi ve tendo iyileşme süresince tarsal eklem hareketlerinin kisitlanmasidir $^{2,8,9}$. Sunulan bu olgu ile travmatik aşil tendo rupturunun operatif sağaltımında uygulanılan kompresyon vidası ile geçici calceneo-tibial fiksasyonun postoperatif klinik, radyolojik ve ultrasonografik bulgularının rapor edilmesi ve kullanılan fiksasyon tekniğinin klinik pratisyenlere tanıtılması amaçlanmıştır.

\section{Vaka Geçmişi}

Merinos 1rk1, 1,5 yaşlı bir koyun, sağ arka ekstremitesine basamama şikayeti ile Uludağ Üniversitesi Veteriner Fakültesi Hayvan Hastanesi Cerrahi Klinikleri'ne getirildi. Hasta sahibi, problemin yaklaşık 15 gün önce sebebi bilinmeyen bir şekilde ahırda şekillendiğini belirtti.

Koyunun genel muayene bulgular1 normaldi ancak inspeksiyonda hayvanın sağ metatarsusu üzerine basarak ayakta durduğu görüldü (Şekil 1). Tuber calcanei etrafinda ve proksimale doğru uzanan yumuşak doku şişkinliği saptand1. Ortopedik muayenede kemik dokuya ilişkin bir patoloji görülmedi. Sol arka ekstremite ile yapılan karşılaştırmalı muayenede sağ arka ekstremitenin aşil tendosunda gevşeklik olduğu fark edildi. Bölgede akut yangı bulguları (ağrı, 1S1 artış1, renk değişikliği) saptanmadı. Radyolojik muayenede, sağ tarsal eklemin al1nan medio-lateral radyografisinde tuber calcanei etrafinda yumuşak doku opasitesinde şişkinlik görüldü. Ultrasonografik muayenede, diğer ekstremitedeki tendo ile karşılaştırıldığında longitudinal olarak aşil tendosunun spesifik ekojenite ve bütünlüğü gözlenmedi. Tuber calcanei'den bir miktar devam eden tendo görünümü sonrasında arada anekoik bir alanın mevcut olduğu (efüzyon?) ve devamında tekrar devam eden bir tendo görünümünün varlığı saptand1 (Şekil 2).

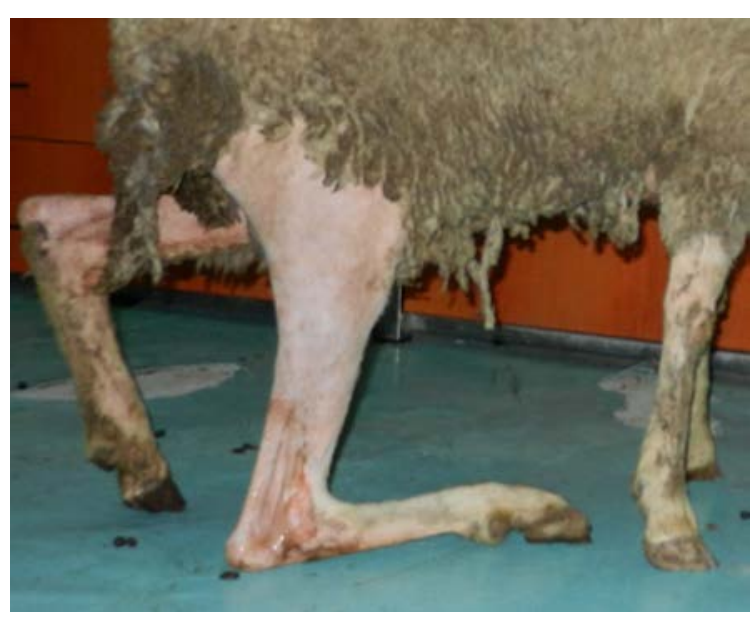

Şekil 1. Olgunun preoperatif klinik görünümü.

Figure 1. Preoperative clinical apperance of the case.

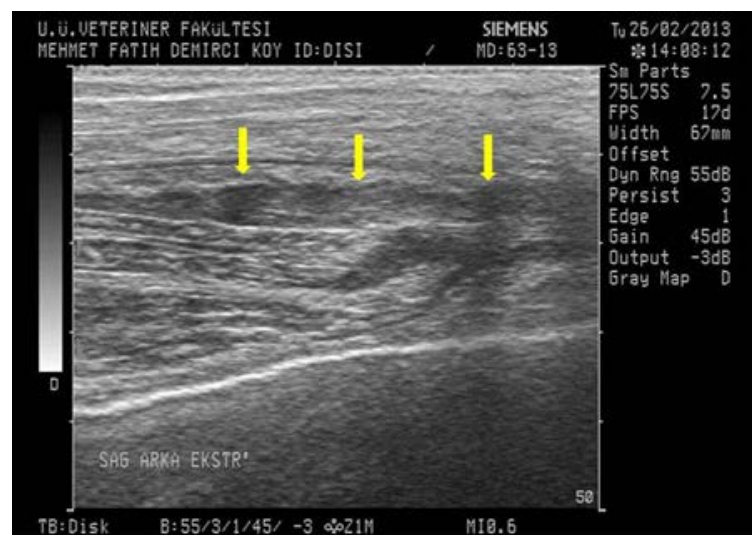

Şekil 2. Ultrasonografik longitudinal görünümde anekoik alanlar (efüzyon?) (oklar) ve tendo bütünlügünün olmaması bozulma.

Figure 2. In the ultrasonographic longutidunal view, anechoic areas (effusion) (arrows) and lack of the tendon continuity.

Klinik, radyolojik ve ultrasonografik muayene bulguları temelinde olgumuzda sağ aşil tendo rupturu tanısı konuldu. Hasta sahibinin bilgilendirilmesi ve tedavi isteği göz önüne alınarak olgunun operatif müdahale ile tedavisine karar verildi.

Preoperatif olarak $0,1 \mathrm{mg} / \mathrm{kg}$, im. xylazine $\mathrm{HCl}$ (Alfazine ${ }^{\circledR}$, Egevet, Türkiye) yapıldı ve $8 \mathrm{mg} / \mathrm{kg}$, im. ketamin HCl (Alfamine ${ }^{\circledR}$, Egevet, Türkiye) ile genel anesteziye giriş sağlandı. Anestezinin idamesi 1/1 oranında ketamin $\mathrm{HCl}$ ve diazepam $\left(0,2 \mathrm{mg} / \mathrm{kg}\right.$, iv.) (Diazem ${ }^{\circledR}$, Deva, Türkiye) kombinasyonu kullanılarak gerçekleştirildi.

Hasta operasyon masasına sağ lateral olarak yatırıldı. Bölgenin tıraş, dezenfeksiyon ve antisepsisi sonrası tibianın medialinde ve distal- 
de tuber calcanei'ye kadar yaklaşık $10 \mathrm{~cm}$ 'lik düz bir ensizyon yapıldı. Derialtı dokuların diseksiyonu sonrasında tendonun rupture olduğu kısma ulaşıldı. Tuber calcanei'ye yapışma yerinin yaklaşı $1 \mathrm{~cm}$ proksimalinde tendonun kopmuş ve tendo uçlarının yapısının bozulduğu görüldü. Tendo uçları transversal olarak kesilip düzeltildikten sonra 2 no absorbe olan dikiș materyali ile (Vicryl Plus ${ }^{\circledR}$, Ethicon, USA) tendo uçları karşı karşıya getirilerek BunnellMayer tendo dikişi ile tespit edildi. Peritendinöz kısım 3/0 no absorbe olan dikiş materyali ile (Vicryl Plus ${ }^{\circledR}$, Ethicon, USA) basit ayrı dikişlerle karşılaștırılarak dikildi. Tarsal eklemi tendo iyileşinceye kadar geçici hareketsizleştirmek amaciyla tuber calcanei'den tibianın distal diafizer kısmına yönelen bir kompresyon vidası (5 $\mathrm{mm}$ çap ve $6 \mathrm{~cm}$ uzunlukta) ile eklemin fiksasyonu sağlandi. Fiksasyon sonrasında bölgede ensize ve disseke edilmiş yumuşak dokular rutin olarak cerrahi dikişlerle kapatıldı. Operasyon bölgesinin postoperatif radyolojik incelemesi gerçekleştirildi (Şekil 3).

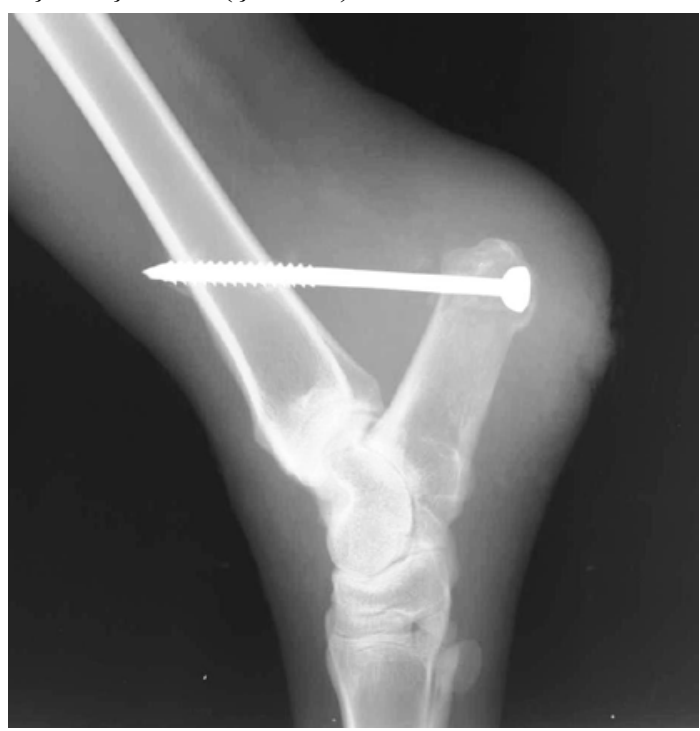

Şekil 3. Postoperatif calcaneo-tibial uygulanmıs kompresyon vidasinin radyolojik görünümü.

Figure 3. Postoperative radiological appearance of the calceneo-tibial applied compression screw.

Lokal olarak operasyon bölgesinin pansumanı gerçekleştirildi ve 5 gün süreyle postoperatif antibiyotik (oksitetrasiklin, $10 \mathrm{mg} / \mathrm{kg}$, im.) ve analjezi (fluniksin meglumin, $1 \mathrm{mg} / \mathrm{kg}$, iv.) uygulaması hasta sahibine önerildi. Hastanın kliniklerimize düzenli aralıklarla getirilmesi istendi.

Postoperatif 10. günde hasta kliniğe getirildiğinde operasyon bölgesine ilişkin herhangi bir yangısal tablo gözlenmedi. Deri dikişleri alındı ve radyolojik olarak uygulanılan calcaneo-tibial kompresyon vidasının yerinde olduğu görüldü. Herhangi bir komplikasyonla karşılaş1madi.

Hastanın postoperatif 2. ayda yapılan ultrasonografik ve radyolojik incelemesi sonucu gözlenen bulgular dikkate alınarak operasyonla uygulanılan vida çıkartıldı (Şekil 4). Vidanın çıkartılmasını takiben hayvanın ayağını normal olarak kullanabildiği gözlendi (Şekil 5).
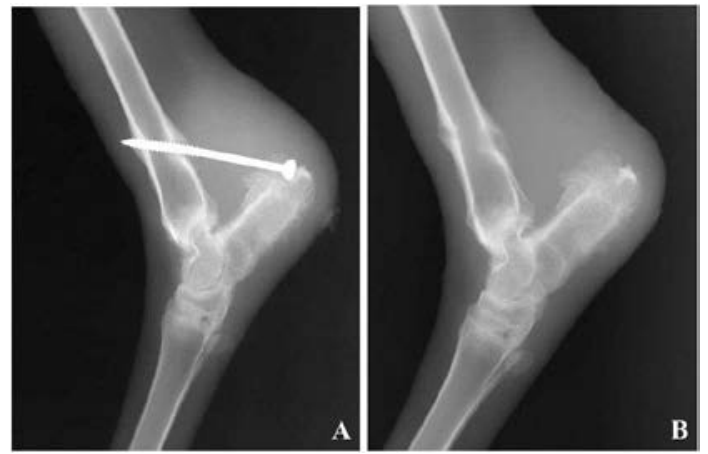

Sekil 4. Postoperatif 2. ayda calcaneo-tibial kompresyon vidası çıkarılma öncesi (A) ve sonrasındaki $(\boldsymbol{B})$ radyolojik görünümler.

Figure 4. Radiological views before (A) and after $(B)$ removing of the calceneo-tibial compression screw at postoperative 2nd month.

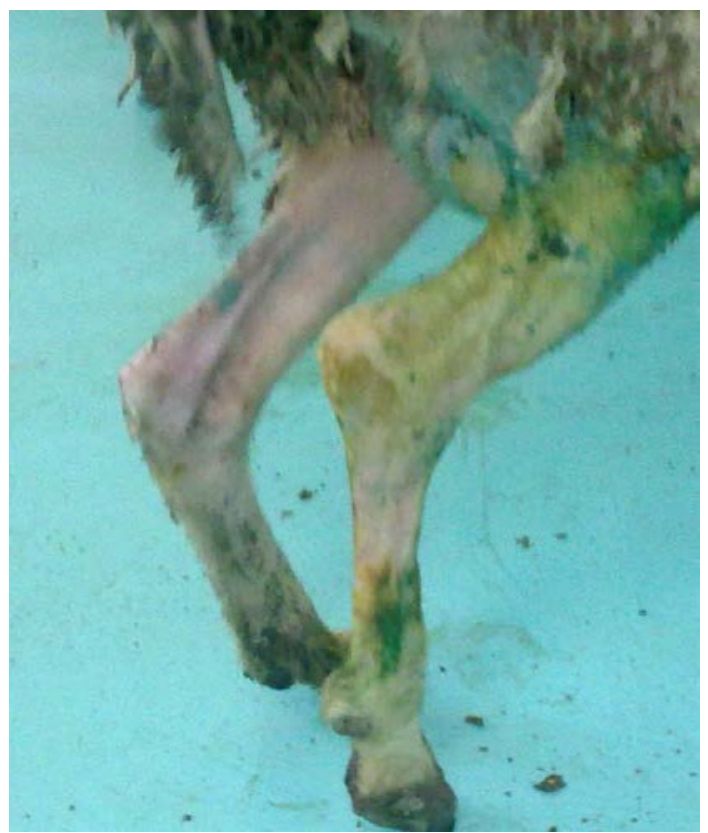

Şekil 5. Postoperatif 2. ayda calcaneo-tibial kompresyon vidası çıkarıldıktan sonraki olgunun klinik görünümü.

Figure 5. Clinical appearance of the case following removing of the calcaneo-tibial compression screw at postoperative 2nd month. 


\section{Tartışma}

Tendo cerrahisinde yer alan araştırmaların erken tendo iyileşmesi ve iyileşme sonrası fonksiyonun sağlanması, kullanılan operatif yöntem ve tendo dikiş tekniği, tendo hareket süresinin kısıtlanması, fibrozisi hızlandırma ve adezyonu önleme gibi sorunlara yönelik olduğu görülmektedir ${ }^{3-7}$. Sunulan klinik olgumuzda tendo iyileşmesi ve erken fonksiyonel dönüşü sağlamaya yönelik uyguladığımız kompresyon vidası ile calcaneo-tibial fiksasyon tekniği kullanarak tendo hareketinin önlenebileceği ve erken fonksiyonel dönüş kazanılabileceği rapor edilmiştir.

Aşil tendosu rupturlarında tendonun tüm anatomik unsurları ya da parsiyal olarak sadece $\mathrm{m}$. gastrocnemious veya $\mathrm{m}$. flexor digitorum superficialis' in zedelenmesi ile karşılaşılmaktadir ${ }^{1,2,6,7}$. Klinik olarak, tendo kopuğunun total veya parsiyel oluşuna bağlı tarsal eklemde değişik derecelerde fleksiyon konumu gözlenmektedir. Total kopmalarda tarsal eklemde hiperfleksiyon ve basışın tamamen metatarsuslar üzerine olduğu, parsiyel kopmalarda ise kopan fibril sayısına göre, tarsal eklemin değişik derecelerde fleksiyonu görülmektedir. Kopmalar tendonun orijininde, kas ipliklerinde veya iskelet insersiyonlarında olabilmektedir ${ }^{6}$. Olgumuzun klinik sunumunda sağ arka ekstremitesini kullanırken basışın metatarsusların tamamen yere temasıyla olduğu görüldü. Preoperatif muayene (klinik, radyolojik ve ultrasonografik) sonuçları ve intraoperatif bulguları, aşil tendosunda total bir rupturun şekillendiğini gösterdi.

Tendo rupturlarında kopan tendo uçlarını karşı karşıya getirmek için değişik dikiş materyelleri ile uygulanılan dikiş teknikleri kullanılmaktadır. En yaygın uygulanan yöntem termino-terminal tenorafi'dir. Termino-terminal tenorafi, tendonun ilk uzunluğunun ve çapının korunması, ayrıca teknik olarak kolaylığı nedeniyle avantaj sağlamaktadır. Kullanılan tendo dikiş yöntemleri: Bunnell-Mayer, Mason-Allen, modifiye Kessler ve Krockow'dir. Yuvarlak ve 2 $\mathrm{cm}$ den daha uzun tendolarm anastomozunda Bunnell-Mayer, $2 \mathrm{~cm}$ 'den daha kisa ve yuvarlak tendolar için Bunnell dikişi uygulanması gerekmektedir ${ }^{1,2,6,7}$. Olgumuzda operatif olarak kopan aşil tendosunun ucuca getirilerek BunnelMayer dikişi ile tespiti ve peritendinöz kısımlarında karşı karşıya dikilerek basit ayrı dikişıerle tenorrafisi uygulandi.
Damardan fakir olan tendo dokusunda metabolizmal faaliyet ve buna bağlı olarak da iyileşme oldukça yavaştır. Operasyon ya da yaralanmaya bağlı tendo yaralarının iyileşmesi, tendoyu saran k1lffların proliferasyonu ile gerçekleşmektedir ${ }^{1,2}$. Uygun koşullarda 2 haftalık bir süre içerisinde tendodaki sikatrisyel doku oluştuğundan bu sürede tendo hareketsiz bırakılmalıdır. Kollajen fibrillerin organizasyonu ile sonuçlanan yeni oluşum aşaması ikinci haftadan sonra başlamakta ve tendonun bu süreden itibaren aşamalı olarak hareketlendirilmesi gerekmektedir ${ }^{2}$. Olgumuzda postoperatif aşil tendosunun klinik iyileșmesi șekilleninceye kadar tarsal eklemin hareketsizliği sağlanmıştır. Postoperatif 2. ayda fiksasyon vidasını çıkarttığımizda tendonun normal fonksiyonunu yerine getirdiği ve tarsal eklemin normal konumunu muhafaza ettiği görülmüştür.

Tendolarda uygulanılan cerrahi girișimlerden sonra tendoların kesin hareketsizliği (immobilizasyon) sağlanmalıdır. Aşil tendosu rupturlarında tenorafi sonrası tarsal eklemin hareketsizliğini sağlamak için genellikle calcaneus ve tibianın distalinde yapılan germe teli uygulaması ile tarsal eklemin fleksiyonu önlenmekte, ya da atel destekli bandaj (eksternal fiksasyon) kullanılmaktadır ${ }^{2-4,6}$. Hareketli köpeklerde calcaneus'tan tibiaya doğru yönlendirilen bir vida ile tarsal eklemin tespitinin sağlanabileceği bildirilmiştir ${ }^{8}$. Tüm bu uygulamalar tendonun gerginliğini azaltmaya yönelik 3 haftadan 3 aya kadar kullanılmaktadır ${ }^{2-4,6,8}$. Sunulan olgumuzda da tarsal eklemin postoperatif dönemde hareketsizliğini sağlamaya yönelik olarak eksternal fiksasyon yöntemi değil internal fiksasyon tekniğinin uygulanması düşünülmüştür. Bu maksatla daha önce bir köpekte uygulandığ gibi $^{8}$ bir kompresyon vidası ile calcaneo-tibial fiksasyon tekniğginin koyunlarda da başarılı bir teknik olabileceği görülmüştür.

\section{Kaynaklar}

1. Alkan, F., Üzcü, C., Ortatatlı, M., Ceylan, C., Karaman, M., 2002. Köpeklerde tendo adezyonlarının önlenmesinde fascia lata otogreftinin kullanımı. Turk. J. Vet. Anim. Sci., 26, 957-964.

2. Candaş, A., Sağlam, M., 1987. Bir köpekte karş1laşılan bilateral aşil tendosu rupturu ve tenorafi'si. A.Ü. Vet. Fak. Derg., 34, 89-96.

3. Cihan, M., Özaydın, İ., 1999. Koyunlarda fibrin adeziv ile deneysel tenorafi. Kafkas Univ. Vet. Fak. Derg., 5, 103-112. 
4. Dar, S.H., Fazili, M.R., Makhdoomi, DM., 2012. Surgical management of achilles tendon rupture in a sheep. Intas. Polivet., 13, 246-248.

5. Görgül, O.S., 2007. Ruminant Cerrahisi. Uludağ Üniversitesi Veteriner Fakültesi Yayınları. Yayın no. 2.04-035-0474, Bursa, sf. 145-146.

6. Görgül, O.S., Yanık, K., 1982. Bir keçide karş1laştı̆̆ımız aşil tendosunun bilateral muskulotendinöz rupturunun operatif sağıtımı. A.Ü. Vet. Fak. Derg., 29, 227-234.

7. Velavan, A., Sivaraman, S., Krishnakumar, K., 2012. Achilles tendon rupture and its clinical management in an ewe. Intas. Polivet., 13, 249250.

8. Worth, A.J., Danielsson, F., Bray, J.P., Burbidge, H.M., Bruce, W.J., 2004. Ability to work and owner satisfaction following surgical repair of common calcanean tendon injuries in working dogs in New Zealand. New Zeal. Vet. J., 52, 109116.

9. Yıldırım, Y., Saygı, B., Kara, H., Çabukoğlu, C., Esemenli, T. 2006. Aşil tendonu tamirinde kullanılan dikiş materyallerinin tendonu tutma kapasiteleri. Acta Orthop. Traumatol. Turc., 40, 164168. 
